EXTENDED REPORT

\title{
Randomised controlled trial comparing the effect of brimonidine and timolol on visual field loss after acute primary angle closure
}

\author{
T Aung, F T S Oen, H-T Wong, Y-H Chan, B-K Khoo, Y-P Liu, C-L Ho, J See, L H Thean, \\ A C Viswanathan, S K L Seah, P T K Chew
}

See end of article for authors' affiliations

Correspondence to:

Dr Tin Aung, Singapore National Eye Centre, 11

Third Hospital Avenue

Singapore, Singapore

168751, Singapore;

tin11@pacific.net.sg

Accepted for publication 23 April 2003

\begin{abstract}
Aim: To compare the effect of brimonidine and timolol in reducing visual field loss in patients with acute primary angle closure (APAC).

Methods: In addition to standard acute medical treatment, patients presenting with APAC were randomised to either brimonidine $0.2 \%$ or timolol $0.5 \%$ upon diagnosis, then twice daily for 4 weeks. After laser peripheral iridotomy (LPI), subjects underwent three baseline perimetry tests during the first week, and then at weeks $4,8,12$, and 16. Pointwise linear regression analysis was applied to the field series of each of these subjects starting with the third test (total of five tests per subject). Progression was defined as a significant regression slope $(p<0.05)$ showing $1 \mathrm{~dB}$ per year or more of sensitivity loss at the same test location in the series. Patients were also compared for prevalence of abnormal fields at 16 weeks, which was defined as an abnormal glaucoma hemifield test result and/or corrected pattern standard deviation outside the $95 \%$ confidence limits.

Results: 59 subjects ( 31 in the brimonidine group; 28 in the timolol group) completed the study. There were 47 females (79.7\%), the majority of subjects (94.9\%) were Chinese and the mean age was 59.2 (SD 7.2) years. There were no significant differences between the two groups with respect to demographic features, presenting intraocular pressure (IOP), duration of symptoms, time from presentation to LPI, or mean IOP at each study visit. Over the 16 week study period, despite adequate statistical power, no difference was found between groups in terms of the number of patients with progressing locations, the mean number of progressing locations per subject, or the mean slope of the progressing locations. Nine $(29 \%)$ subjects in the brimonidine group and $10(35.7 \%)$ in the timolol group were found to have significant visual field defects at 16 weeks $(p=0.58)$. 15 out of these 19 subjects $(78.9 \%)$ already had these visual field defects in the first week.

Conclusions: In the first 16 weeks after APAC, there was no difference in the prevalence of visual field defects or rate of visual field progression between brimonidine and timolol treated groups.
\end{abstract}

A cute primary angle closure (APAC) is a potentially blinding ocular condition. The incidence of APAC is especially high in Asia, ${ }^{1}$ where APAC episodes are frequently severe. ${ }^{2}$ Compared to eyes of white people, the condition in Asian eyes may have different long term response to laser therapy. ${ }^{3}$ The incidence and type of visual field damage resulting from an episode of APAC is not well established, and the degree of visual field loss can vary in severity. ${ }^{4-8}$ In one study, $38 \%$ of APAC patients were found to have significant visual field defects 6 months after APAC, ranging from severe field loss to defects like arcuate nerve fibre bundle type defects. ${ }^{8}$ Delay in presentation and unresponsiveness to medical treatment in termination of the acute attack are associated with an unfavourable outcome. ${ }^{8} 9$ It is not known when visual field defects become established, but visual field losses have been documented from as early as a few days after presentation, ${ }^{7}$ to months after the acute episode. ${ }^{58}$ However the chronological change in the visual field has not been studied prospectively after APAC.

Brimonidine tartrate is a highly selective alpha-2-adrenergic agonist that acts by decreasing aqueous production, and increasing uveoscleral (secondary) outflow. ${ }^{10}$ In addition to their known effect of lowering intraocular pressure, alpha-2adrenoreceptor agonists are thought to exert a neuroprotective effect in experimental models of optic nerve injury. ${ }^{11-16}$ In a study conducted by Yoles et al, ${ }^{11}$ the effect of brimonidine on neuronal damage was studied after partial crush injury of the rat optic nerve. Treatment immediately after injury with intraperitoneal brimonidine resulted in a dose dependent attenuation of the injury, induced decrease in compound action potential amplitude of the optic nerve, and reduced loss of retinal ganglion cells 2 weeks after injury. ${ }^{11}$ Such animal models are believed to simulate secondary neuronal degeneration of the optic nerve after trauma caused by pressure, ischaemia, or hypoxic injuries. It is thought that the mechanism involved may resemble the optic nerve damage seen in glaucoma, ${ }^{17}$ and may explain why glaucomatous neuropathy continues to progress even after its primary insult, high intraocular pressure (IOP), has been alleviated or attenuated.

Acute primary angle closure may be an appropriate human model to study the potential neuroprotective effect of different compounds. The IOP in APAC is usually extremely high $\quad$ (50-70 $\mathrm{mm} \mathrm{Hg}$ ) and, occurring acutely, neuronal damage may occur or may be triggered off to occur as a result of this insult. However, at any given time, it is likely that there are many other neurons that are viable, but vulnerable to the hostile extracellular milieu. Adding a potential neuroprotectant to the standard treatment regimens may 
reduce secondary neuronal damage and result in less overall optic nerve damage and better preservation of vision.

The purpose of this clinical trial was to evaluate the potential of brimonidine in reducing optic nerve damage in the first 16 weeks after APAC. Patients were randomised to have either brimonidine or timolol added to the initial medical treatment of APAC. After resolution of the acute episode and treatment with laser peripheral iridotomy (LPI), all IOP lowering drugs were stopped except for the study medications, which were continued for 4 weeks. Visual field testing was performed thrice in the first week after LPI to obtain a baseline, and then at 4 weekly intervals until 16 weeks after APAC. Both medications were expected to have similar IOP lowering effect, and having controlled the influence of IOP, the visual field series were compared to assess the degree and progression of visual field loss in the two groups.

\section{PATIENTS AND METHODS}

This three centre study was prospectively carried out in Singapore at the Singapore National Eye Centre, Tan Tock Seng Hospital, and the National University Hospital. After obtaining approval from the ethics committees of each centre and by the Ministry of Health of Singapore, a signed informed consent was obtained from all patients before study enrolment. The study was performed according to the Declaration of Helsinki and the Singapore guidelines on "good clinical practice."

Patients 21 years of age or older with unilateral acute primary angle closure (APAC) were eligible. All patients recruited had IOP $>28 \mathrm{~mm} \mathrm{Hg}$ at presentation and had the following clinical features: ocular pain, conjunctival injection, shallow anterior chamber, unreactive pupil, and gonioscopic findings of angle closure. Patients with secondary angle closure, such as lens induced glaucoma, neovascular glaucoma, or uveitis were excluded. Other exclusion criteria were corneal abnormalities, opacities in the media, retinal or neurological abnormalities that would affect the visual field, previous intraocular surgery, previous treatment with glaucoma therapy, previous corneal infection or dry eyes, current use of contact lenses, and known allergy to benzalkonium chloride. Also, a history of asthma or chronic obstructive lung disease, congestive cardiac failure, bradycardia, heart block, cerebrovascular, hepatic or metabolic disease (except diabetes mellitus) was considered reasons for exclusion. Currently pregnant or nursing women, or women considering pregnancy were also excluded, as were patients who participated in another therapeutic drug study within 1 month.

The initial treatment administered to reduce IOP in APAC consisted of acetazolamide (intravenous bolus of $500 \mathrm{mg}$ ), and one drop each of topical pilocarpine $4 \%$ and topical steroids (either dexamethasone or prednisolone acetate). In addition to these treatments, at the time of presentation, patients were randomised (by block randomisation) to two parallel study groups: one group was assigned to treatment with one drop of brimonidine $0.2 \%$ immediately followed by twice daily for a duration of 4 weeks. The other group received timolol $0.5 \%$ immediately, and twice daily thereafter for 4 weeks. All types of medication were dispensed open label as the commercially available preparation, brimonidine $0.2 \%$ (Alphagan, Allergan Inc, Irvine, CA, USA) and timolol maleate $0.5 \%$ (Timoptol, Merck \& Co, Inc, Whitehouse Station, NJ, USA). Patients were instructed to instil the medications at approximately 8 am and 8 pm each day.

The priority in the initial management of APAC patients was to break the acute episode, and flexibility was permitted for managing physicians in treatment in order to achieve this objective. Most subjects required further treatment with oral acetazolamide, topical pilocarpine, and topical steroids.
Patients who responded to medical treatment, and experienced reduction of IOP with improved cornea clarity underwent laser peripheral iridotomy (LPI) 1-2 days after presentation. Those who could not undergo LPI, such as those with unresolved APAC because of unresponsiveness to medical treatment were withdrawn from the study. Such patients required other management for APAC such as laser peripheral iridoplasty or trabeculectomy. Patients who underwent LPI but had visual acuity persistently worse than 6/18 during the first week after LPI were also withdrawn as the poor visual acuity may affect visual field performance. All IOP lowering medication was stopped within a week of LPI, except for the study medications, which continued until week 4 .

Patients underwent visual field testing in the first week after LPI (see below). There were four subsequent scheduled visits; at weeks 4, 8, 12, and 16 . The schedule of examinations and procedures is presented in table 1 . At each visit, medical and ocular history was taken. Visual acuity, slit lamp examination, ophthalmoscopy and measurement of the IOP were performed. At any study visit, subjects with visual acuity worse than 6/18 were withdrawn from the study. At any visit, those who had uncontrolled IOP requiring medication additional to the study medication or who required filtering surgery were also withdrawn.

Adverse events were monitored carefully throughout the study. An adverse event was defined as any undesirable event occurring in a subject regardless if it was considered related to the investigational drug. A serious adverse event was defined as an event that was potentially fatal, life threatening, permanently disabling, requiring hospitalisation, or requiring intervention to prevent permanent impairment or damage.

\section{Visual field testing}

As soon as the APAC attack had been successfully terminated, LPI performed, and the corneal clarity improved, patients underwent baseline automated white on white threshold perimetry (program 24-2, model 750, Humphrey Instruments, Dublin, CA, USA). The first test was done within 1-2 days after LPI, and the test was repeated two more times during the first week. The first two visual field tests for all subjects were discarded from the analyses to allow for learning effects. Patients subsequently underwent visual field testing at weeks 4, 8, 12, and 16 (a total of five tests analysed per subject). Visual fields were included only if the false positive and negative responses were less than $33 \%$.

The primary outcome measure was based on pointwise linear regression analysis applied to the field series of each of these subjects. Progression was defined as the presence of a significant regression slope $(p<0.05)$ showing $1 \mathrm{~dB}$ per year or more of sensitivity loss at the same test location in the series. The number of subjects with progressing points, the mean number of progressing points per subject, and the mean slope for the progressing points were evaluated. The secondary outcome measure was the prevalence of abnormal visual field tests at week 16. Patients were defined as having abnormal fields if there was an abnormal glaucoma hemifield test result and/or corrected pattern standard deviation outside the $95 \%$ limits.

\section{Statistical evaluation}

The primary outcome measure was the number of progressing points per patient on pointwise linear regression analysis from week 1 to week 16. A trial size of 60 randomised to timolol and to brimonidine was calculated to be sufficient to detect a $30 \%$ difference in the number of patients with progressing points in the visual fields in the two groups with a $5 \%$ two sided test level of significance and power of $75 \% .{ }^{18}$ It 
Table 1 List of schedule and procedures

\begin{tabular}{|c|c|c|c|c|c|c|c|}
\hline & 1-2 days LP1 & 2-4 days $L P 1$ & Week 1 & Week 4 & Week 8 & Week 12 & Week 16 \\
\hline History & $x$ & & & $x$ & $x$ & $x$ & $x$ \\
\hline Gonioscopy & $x$ & & & & & & \\
\hline Visual field & $x$ & $x$ & $x$ & $x$ & $x$ & $x$ & $x$ \\
\hline Ophthalmoscopy & $x$ & & & & & & $x$ \\
\hline Visual acuity & $x$ & & $x$ & $x$ & $x$ & $x$ & $x$ \\
\hline Slit lamp & $x$ & & & $x$ & $x$ & $x$ & $x$ \\
\hline IOP & $x$ & & $x$ & $x$ & $x$ & $x$ & $x$ \\
\hline
\end{tabular}

was estimated that, after randomisation, $10-20 \%$ of the APAC patients would not respond to initial medical treatment and not undergo LPI. After LPI, it was expected that a further $10-20 \%$ of patients would not complete the trial and would withdraw from the study. Taking into consideration the patients expected to withdraw from the study, a sample of 100 APAC patients was calculated to be required for recruitment. All statistical tests were conducted at the 5\% level using SPSS software version 11.0 (Statistical Package for Social Sciences, Chicago, IL, USA). Data management was maintained on Clintrial 4.2 (www.phaseforward.com).

\section{RESULTS}

A total of 127 patients were recruited into the study and underwent randomisation. On the first day after randomisation, 10 patients were withdrawn from the study because of violation of the inclusion/exclusion criteria and 10 subjects changed their minds and refused to continue in the study. Fifteen subjects could not undergo LPI as a result of poor corneal clarity or non-response to medical therapy, leaving 92 subjects in the study who underwent LPI.

In the first week after LPI, 20 subjects were withdrawn from the study ( 15 subjects had visual acuity worse than 6/ 18 , three subjects had uncontrolled IOP requiring multiple medication, one subject could not perform perimetry, and one subject refused to participate further), which left 72 subjects who underwent visual field tests in week 1. From weeks 4 to 16,13 subjects were withdrawn from the study ( six subjects underwent trabeculectomy for uncontrolled IOP, two subjects developed visual acuity worse than 6/18, four subjects were lost to follow up, and one subject refused to continue in the study). Thus, 59 subjects completed the entire study proper (31 subjects in the brimonidine group and 28 in the timolol group), and unless otherwise stated, the following analyses will take into account these 59 subjects.

Table 2 shows the baseline demographic characteristics. There were 47 females $(79.7 \%)$, and the majority of subjects (94.9\%) were Chinese. The mean age was 59.2 (SD 7.2) years (range 45.8-82.4 years). There were no significant differences between the two groups with respect to sex, race, and age.

There was no difference between groups for mean presenting IOP, duration of symptoms, or number of days from presentation to LPI (as summarised in table 3). The visual field global indices, MD and CPSD of the baseline visual fields in the two groups are also shown in table 3. Table 4 lists the mean IOP at different study visits. There was no significant difference in the IOP between the two groups for each time point in the study.

\section{Visual fields}

At week 1 (that is, following laser iridotomy and resolution of the acute attack), 35 (59.3\%) of the 59 patients had normal visual fields, while the remaining $24(40.7 \%)$ were found to have reproducible defects. This consisted of $10(32.3 \%)$ subjects in the brimonidine group and $14(50 \%)$ in the timolol group. The majority of these defects were combined superior and inferior nerve fibre bundle type arcuate defects (fig 1).

By week 16, the total number of patients with reproducible field defects had decreased to 19 (32.2\%). This consisted of nine $(29 \%)$ subjects in the brimonidine group and $10(35.7 \%)$ in the timolol group $(p=0.58)$. Fifteen of these 19 subjects $(78.9 \%)$ already had these visual field defects at week 1 , but four subjects who were normal at baseline developed a new defect by 16 weeks (fig 2). Of the 24 patients who had started off with abnormal fields at week 1 , nine were found to have "normalised" by week 16 (fig 3). Overall, baseline visual fields were found to be predictive of outcome at 16 weeks $(\mathrm{p}<0.001, \mathrm{OR}=12.9,95 \%$ CI 3.4 to 48.8$)$.

In terms of progression over the 16 weeks, six (20\%) subjects in the brimonidine group and five $(17.9 \%)$ in the timolol group were found to have progressing locations $(p=0.84)$. There was no difference found in the mean number of progressing locations per subject, or the mean slope of the progressing locations (table 5).

\begin{tabular}{|c|c|c|c|c|}
\hline & Overall $(n=59)$ & Brimonidine $(n=31)$ & Timolol $(n=28)$ & p Value \\
\hline \multicolumn{5}{|l|}{ Sex } \\
\hline Male & $12(20.3 \%)$ & 7 (58.3\%) & 5 (41.7\%) & \multirow[t]{2}{*}{0.65} \\
\hline Female & $47(79.7 \%)$ & $24(51.1 \%)$ & $23(48.9 \%)$ & \\
\hline \multicolumn{5}{|l|}{ Race } \\
\hline Chinese & $56(94.9 \%)$ & $30(53.5 \%)$ & $26(46.4 \%)$ & \multirow[t]{3}{*}{0.22} \\
\hline Malay & $2(3.4 \%)$ & $0(0 \%)$ & $2(100 \%)$ & \\
\hline Others & $1(1.7 \%)$ & $1(100 \%)$ & $0(0 \%)$ & \\
\hline \multicolumn{5}{|l|}{ Age } \\
\hline Mean (SD) & $59.2(7.2)$ & $60.9(7.2)$ & $57.5(6.9)$ & \multirow[t]{3}{*}{0.10} \\
\hline Range & 45.8 to 82.4 & 45.8 to 82.4 & 46.8 to 69.8 & \\
\hline Median & 59.7 & 61.8 & 56.7 & \\
\hline \multicolumn{5}{|l|}{ Laterality } \\
\hline Right & $32(54.2 \%)$ & $19(59.4 \%)$ & $13(40.6 \%)$ & \multirow[t]{2}{*}{0.30} \\
\hline Left & $27(45.8 \%)$ & $12(44.4 \%)$ & $15(55.6 \%)$ & \\
\hline
\end{tabular}




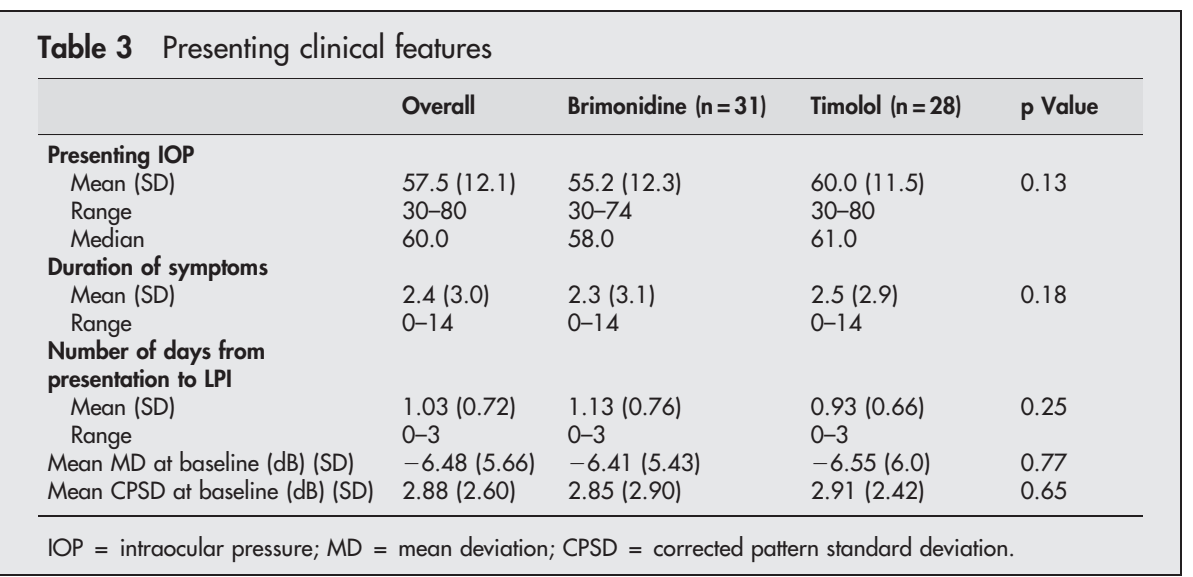

\section{Adverse events}

There were few adverse events experienced by the subjects. The commonest adverse event was conjunctival hyperaemia, which was experienced by two subjects in the brimonidine group and five subjects in the timolol group. In addition, two subjects in each group had mild conjunctival chemosis.

\section{DISCUSSION}

This is the first randomised controlled trial to prospectively assess the neuroprotective effect of medications on visual field outcome after an episode of APAC. By randomising patients to medications with similar IOP reduction, it is thought that any difference in visual outcome found in the study groups may be attributable to the addition of a neuroprotective agent to the treatment regimen. Overall, only 11 out of 59 subjects $(18.6 \%)$ were found to have significant progressing points (with regression slope of $1 \mathrm{~dB}$ per year or more, using pointwise linear regression analysis) in their visual fields over 16 weeks. Comparing the groups, there were similar numbers of patients with progressing locations, mean number of progressing locations, and mean slope of progressing locations. This lower than anticipated prevalence of subjects with progressing locations is likely to have limited the power of the study to detect a difference between the two groups.

No gold standard exists to define progressive visual field loss in glaucoma, as intratest and intertest variability of threshold sensitivity make the diagnosis of progression a difficult task. Various methods of determining visual field progression have been described including clinical judgment of sequential visual field results, defect classification systems such as the Advanced Glaucoma Intervention Study (AGIS) ${ }^{19}$ and the Collaborative Initial Glaucoma Treatment Study, ${ }^{20}$ and event analyses such as the glaucoma change probability (GCP) program available on the Humphrey analyser. Trend analyses, which evaluate test parameters sequentially to determine temporal patterns, have the potential to discriminate subtle progressive loss from test variability. ${ }^{21}$ Linear regression may be the most appropriate trend analyses model to identify progressive glaucomatous visual field loss, ${ }^{22}$ and it has been used on global indices, ${ }^{23}$ sectors of the visual field, ${ }^{24} 25$ and pointwise individual test locations. ${ }^{21} 2627$ The advantage of pointwise linear regression analysis, which is the method used in this study, is that important spatial

\begin{tabular}{|c|c|c|c|c|}
\hline & Overall & Brimonidine $(n=31)$ & Timolol $(n=28)$ & p Value \\
\hline \multicolumn{5}{|l|}{ Presenting IOP } \\
\hline Mean (SD) & $57.5(12.1)$ & $55.2(12.3)$ & $60.0(11.5)$ & \multirow{3}{*}{0.13} \\
\hline Range & $30-80$ & $30-74$ & $30-80$ & \\
\hline Median & 60.0 & 58.0 & 61.0 & \\
\hline \multicolumn{5}{|l|}{ IOP after LPI } \\
\hline Mean (SD) & $12.4(4.1)$ & $12.6(4.7)$ & $12.3(3.3)$ & \multirow{3}{*}{0.76} \\
\hline Range & $4-22$ & $4-22$ & $5.7-18.7$ & \\
\hline Median & 12.0 & 12.0 & 12.0 & \\
\hline \multicolumn{5}{|c|}{ IOP after visual field at week 1} \\
\hline Mean (SD) & $14.3(4.5)$ & $14.4(4.8)$ & $14.2(4.3)$ & \multirow{3}{*}{0.89} \\
\hline Range & $5.3-28.7$ & $6.7-28.7$ & $5.3-24.7$ & \\
\hline Median & 14.0 & 13.7 & 14.0 & \\
\hline \multicolumn{5}{|l|}{ IOP at week 4} \\
\hline Mean (SD) & $16.9(6.5)$ & $17.6(7.2)$ & $16.2(5.6)$ & \multirow{3}{*}{0.39} \\
\hline Range & $6.7-36.7$ & $6.7-36.7$ & $8-32$ & \\
\hline Median & 15.3 & 16.0 & 15.0 & \\
\hline \multicolumn{5}{|l|}{ IOP at week 8} \\
\hline Mean (SD) & $16.9(4.1)$ & $17.8(4.2)$ & $16.0(3.9)$ & \multirow{3}{*}{0.09} \\
\hline Range & $9.7-27.3$ & $10-27.3$ & $9.7-25.7$ & \\
\hline Median & 16.7 & 18.3 & 15.8 & \\
\hline \multicolumn{5}{|c|}{ IOP at week 12} \\
\hline Mean (SD) & $16.9(4.7)$ & $17.0(4.5)$ & $16.8(5.1)$ & \multirow{3}{*}{0.88} \\
\hline Range & $7.3-30.3$ & $7.3-30.3$ & $7.7-26.0$ & \\
\hline & 16.7 & 16.7 & 16.8 & \\
\hline \multicolumn{5}{|c|}{ IOP at week 16} \\
\hline Mean (SD) & $16.5(3.7)$ & $16.5(3.0)$ & $16.5(4.4)$ & \multirow{3}{*}{0.94} \\
\hline Range & $9.3-29.7^{\prime}$ & $10-24$ & $9.3-29.7$ & \\
\hline Median & 16.0 & 17.0 & 16.0 & \\
\hline
\end{tabular}



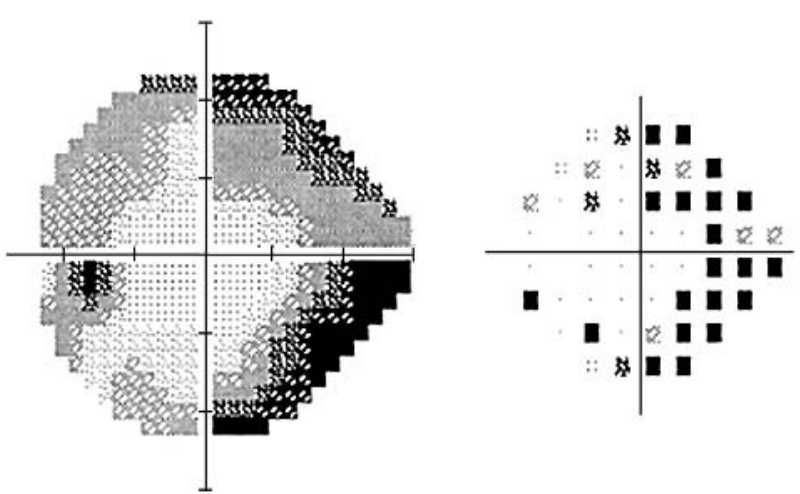

Figure 1 Visual field of a subject who developed a superior and inferior arcuate defect. Left: Grey scale plot; right: pattern deviation plot.

relations between locations that appear to be progressive are preserved rather than being lost by data reduction. ${ }^{28}$ However, there is no consensus as to the pointwise trend analysis outcome measure that is best for determining progression. Varying minimum number of tests and length of follow up, ${ }^{24}{ }^{29}$ as well as different slope criteria, ${ }^{24}{ }^{30-34}$ have been used in previous studies of open angle glaucoma, but such tests have never been employed in studying APAC.

The disease process, especially the mechanism, type, and rate of neuronal damage after APAC, is not established. Any neuronal damage resulting from APAC is thought to occur quite rapidly because of the acute presentation of the disease and extremely high IOPs encountered. In an experimental model of raised IOP in monkey eyes, non-ischaemic changes in ganglion cells were noted after 8 hours. ${ }^{35}$ However, it is not known if the resultant visual loss occurs acutely over hours or days, or if there is a more progressive visual field worsening over weeks or months. There remains the possibility that mild and subclinical optic nerve damage occurs after APAC. For example, specific points in the visual field may have developed reduced retinal sensitivity but this deficit may not be detectable by the method of perimetry used. Current perimetric methods may also not be sensitive enough to detect visual field change over a short period of time after an episode of APAC. It is not known if other perimetric methods such as short wavelength automated perimetry or high pass resolution perimetry would have been more sensitive to detect subtle changes in visual field sensitivity, though these methods have high variability and are subject to lens changes.

Interestingly, there was a low prevalence of visual field defects at 16 weeks after APAC, with the majority of eyes $(67.8 \%)$ having normal visual fields. Only nine (29\%) subjects in the brimonidine group and $10(35.7 \%)$ in the timolol group were found to have a significant visual field defect. Thus, they suffered an episode of acute angle closure but had no evidence of detectable functional damage developing as a sequel of the acute attack. This finding is noteworthy in that it has shown in cases that receive and respond to prompt, intensive medical therapy, APAC is not necessarily a blinding condition. Those with abnormal visual fields tend to develop hemifield defects, consistent with nerve fibre bundle pattern loss. It is difficult to predict risk factors for visual field damage from the characteristics of the acute attack, as there is likely to be inter-individual variation in the ability of eyes to withstand the insult of sudden IOP rise. Although there are conflicting reports of the effect of the duration of attack on the visual field outcome, ${ }^{96}{ }^{37}$ long duration of very high IOP, as in neglected cases of APAC, is likely to eventually cause optic nerve damage. The level of
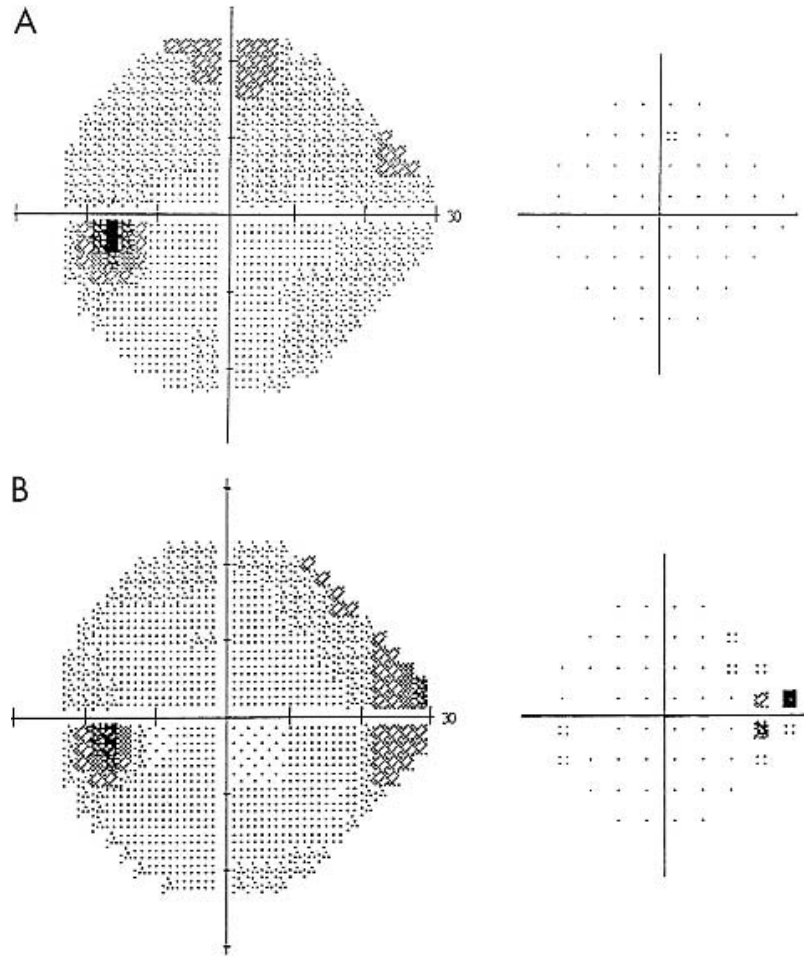

Figure 2 (A) Subject with normal visual field at week 1 (baseline). (B) Same subject with a new visual field defect (nasal loss) at week 16. Left: Grey scale plots; right: pattern deviation plots.

IOP at presentation and the method of treatment however have not been associated with final visual field outcome. ${ }^{8} 938$

Another interesting aspect of this study was that visual field tests performed in the first week after APAC may be predictive of outcome at 16 weeks, although the high rate of withdrawal of study subjects may limit the generalisability of

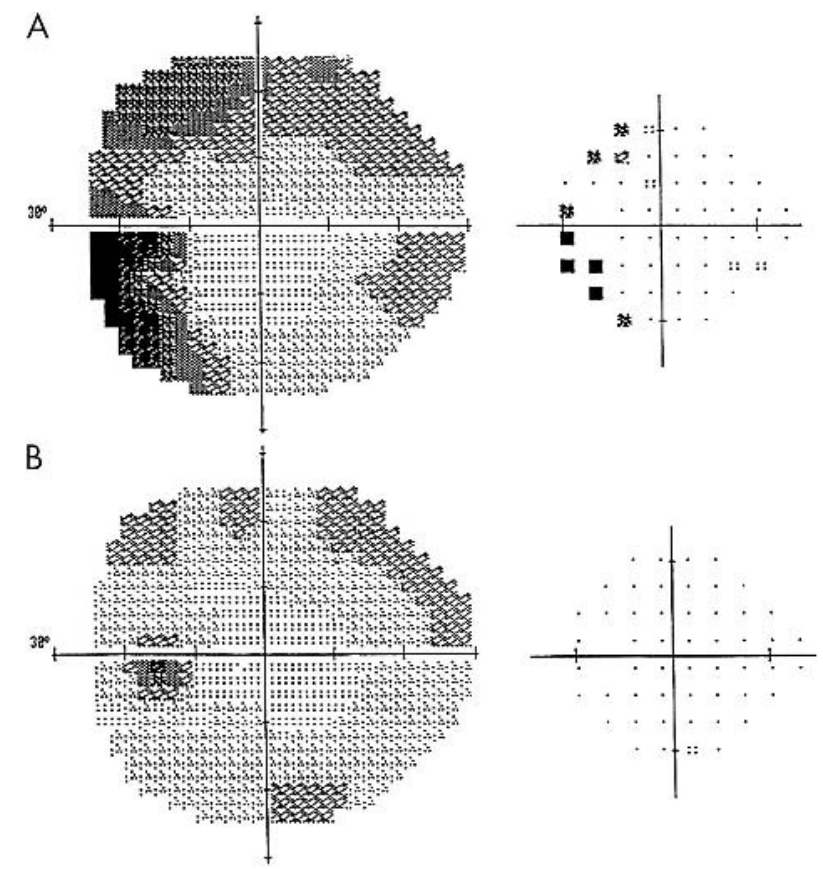

Figure 3 (A) Subject with abnormal visual field at week 1 (baseline). (B) Same subject with subsequently normalised visual field at week 16. Left: Grey scale plots; right: pattern deviation plots. 


\begin{tabular}{|c|c|c|c|}
\hline & Brimonidine $(n=31)$ & Timolol $(n=28)$ & p Value \\
\hline Number of patients with progressing locations & $6(20 \%)$ & $5(17.9 \%)$ & 0.84 \\
\hline Progressing subjects only & Brimonidine $(n=6)$ & Timolol $(n=5)$ & p Value \\
\hline $\begin{array}{l}\text { Number of progressing locations } \\
\text { Mean (SD) } \\
\text { Range } \\
\text { Median }\end{array}$ & $\begin{array}{l}1.83(0.41) \\
1-2 \\
2\end{array}$ & $\begin{array}{l}1.6(1.34) \\
1-4 \\
1\end{array}$ & 0.25 \\
\hline $\begin{array}{l}\text { Slope of progressing locations (dB/year) } \\
\text { Mean (SD) } \\
\text { Range } \\
\text { Median }\end{array}$ & $\begin{array}{l}-1.59(0.85) \\
-3.4 \text { to }-1.0 \\
-1.1\end{array}$ & $\begin{array}{l}-2.18(1.16) \\
-4.2 \text { to }-1.2 \\
-1.65\end{array}$ & 0.08 \\
\hline
\end{tabular}

this finding. Fifteen out of 19 subjects with abnormal visual fields at 16 weeks already had the defect in the first week after APAC. It is not known if these early defects were the result of the acute episode and were detectable early. It is highly likely that these visual field defects could also have occurred as a result of pre-existing chronic glaucoma (before the development of an acute episode), or previous intermittent angle closure glaucoma. ${ }^{39}$ Several subjects had visual field abnormalities that improved and disappeared by the 16th week. It is likely that this improvement was related to learning effects.

The main limitation of the study was the high rate of withdrawal of study subjects, which may have resulted in sampling bias, and the study groups not being fully representative of the APAC population. This was mainly the result of the strict inclusion/exclusion criteria used to keep the two groups constant in terms of IOP and treatment. The withdrawal of subjects included those who could not undergo LPI because of non-responsiveness to medical therapy ( 15 subjects), those with visual acuity worse than 6/18 (17 subjects), and those with uncontrolled IOP who required additional IOP lowering medication apart from the study medication (nine subjects, six of whom underwent trabeculectomy). Many patients also changed their mind and refused to continue in the study (12 subjects), especially in the first few days after agreeing to participate. The likely reason for this is that consent for randomisation was taken at the time of presentation. Having presented acutely, often late at night, many patients agreed to take part in the study but changed their mind later when they were better. There were also several cases of eyes with secondary angle closure glaucoma (particularly neovascular and lens induced glaucoma) misdiagnosed initially as APAC. Other methods of assessing glaucomatous damage such as optic disc imaging or nerve fibre layer measurements were not employed, and these methods may have been useful in recording subtle structural changes.

APAC is a potential human model for studying neuroprotection. The relatively short time frame predicted for nerve damage to occur in the condition may make it feasible to determine the neuroprotective effect of study medications quite quickly. The optimum route of administration of such drugs however is unknown, and it seems unlikely that a topical route of administration will achieve sufficient concentration at or near the optic nerve head to have any significant effect. Elevated IOP models such as APAC may in fact be more representative of glaucomatous damage than experimental optic nerve crush or transection models. It remains to be seen whether individual point retinal sensitivity in the visual field is the best method of assessing outcome in such studies. It is hoped that this study will be an important starting point for further research into the condition, which may in turn offer new opportunities for the design of neuroprotective treatments and lead to improved outcomes for glaucoma.

\section{ACKNOWLEDGEMENTS}

The trial was supported by an unrestricted grant from Allergan. Dr T Aung is also supported by the National Medical Research Council, Singapore.

\section{Authors' affiliations}

T Aung, F T S Oen, C-L Ho, J See, S K L Seah, P T K Chew, Singapore National Eye Centre, Singapore

H-T Wong, B-K Khoo, Tan Tock Seng Hospital, Singapore

Y-H Chan, Y-P Liu, Clinical Trials and Epidemiology Research Unit, Singapore

L H Thean, P T K Chew, National University Hospital, Singapore

A C Viswanathan, Moorfields Eye Hospital, London, UK

P T K Chew, National University of Singapore

Proprietary interest: Nil.

\section{REFERENCES}

1 Seah SK, Foster PJ, Chew PT, et al. Incidence of acute primary angle closure glaucoma in Singapore: an island wide survey. Arch Ophthalmol 1997; 115:1437-40.

2 Hoskins HD Jr, Kass MA. Becker-Shaffer's diagnosis and therapy of the glaucomas: angle-closure glaucoma with pupillary block. St Louis: CV Mosby, 1989:208-37.

3 Aung T, Ang LP, Chan SP, et al. Acute primary angle-closure: long-term intraocular pressure outcome in Asian eyes. Am J Ophthalmol 2001:131:7-12.

4 Douglas GR, Drance SM, Schulzer M. The visual field and nerve head in angle-closure glaucoma. A comparison of the effects of acute and chronic angle closure. Arch Ophthalmol 1975;93:409-11.

5 Dhillon B, Chew PT, Lim ASM. Field loss in primary angle-closure glaucoma. Asia-Pacific J Ophthalmol 1990;2:85-7.

6 Lowe RF. Primary angle-closure glaucoma: a review 5 years after bilateral surgery. Br J Ophthalmol 1973;57:457-63.

7 Bonomi L, Marraffa M, Marchini G, et al. Perimetric defects after a single acute angle-closure glaucoma attack. Graefes Arch Clin Exp Ophthalmol 1999;237:908-14.

8 Aung T, Looi AL, Chew PT. The visual field following acute primary angle closure. Acta Ophthalmol Scand 2001;79:298-300.

9 Wong JS, Chew PTK, Alsagoff A, et al. Clinical course and outcome of primary acute angle closure glaucoma in Singapore. Singapore Med J 1997:38:16-18.

10 Toris CB, Gleason ML, Camras CB, et al. Effects of brimonidine on aqueous humour dynamics. Arch Ophthalmol 1995;113:1514-7.

11 Yoles E, Wheeler LA, Schwartz M. Alpha2-adrenoreceptor agonists are neuroprotective in a rat model of optic nerve degeneration. Invest Ophthalmol Vis Sci 1999:40:65-73.

12 Wheeler LA, Lai R, Woldemussie E. From the lab to the clinic: activation of an alpha-2 agonist pathway is neuroprotective in models of retinal and optic nerve injury. Eur J Ophthalmol 1999;9(Suppl 1):S17-21.

13 Vidal-Sanz M, Lafuente MP, Mayor S, et al. Retinal ganglion cell death induced by retinal ischemia: neuroprotective effects of two alpha-2 agonists. Surv Ophthalmol 2001;45(Suppl 3):S261-7.

14 Wheeler LA, Woldemussie E. Alpha-2 adrenergic receptor agonists are neuroprotective in experimental models of glaucoma. Eur J Ophthalmol 2001;11(Suppl 2):S30-5.

15 WoldeMussie E, Ruiz G, Wijono M, et al. Neuroprotection of retinal ganglion cells by brimonidine in rats with laser-induced chronic ocular hypertension. Invest Ophthalmol Vis Sci 2001;42:2849-55. 
16 Barneby $\mathrm{H}$, for the Brimonidine Study Group. Long term efficacy of brimonidine on IOP lowering. Invest Ophthalmol Vis Sci 1996;37:S1 102.

17 Lynch DR, Dawson TM. Secondary mechanisms in neuronal damage. Curr Opin Neurol 1994;7:175-86.

18 Machin D, Campbell MJ, Fayers PM, et al. Sample size tables for clinical studies, 2nd ed. Oxford: Blackwell, 1997.

19 AGIS investigators. Advanced Glaucoma Intervention Study 2. Visual field test scoring and reliability. Ophthalmology 1994;101:1445-55.

20 Musch DC, Lichter PR, Guire KE, et al. The Collaborative Initial Glaucoma Treatment Study: study design, methods, and baseline characteristics of enrolled patients. Ophthalmology 1999;106:653-62.

21 Fitzke FW, Hitchings RA, Poinoosawmy D, et al. Analysis of visual field progression in glaucoma. Br J Ophthalmol 1996;80:40-8.

22 McNaught Al, Crabb DP, Fitzke FW, et al. Modelling series of visual fields to detect progression in normal-tension glaucoma. Graefes Arch Clin Exp Ophthalmol 1995;233:750-5.

23 Chauhan BC, Drance SM, Douglas GR. The use of visual field indices in detecting changes in the visual field in glaucoma. Invest Ophthalmol Vis Sci 1990;31:512-20.

24 Katz J, Gilbert D, Quigley HA, et al. Estimating progression of visual field loss in glaucoma. Ophthalmology 1997; 104:1017-25.

25 Nouri-Mahdavi K, Brigatti L, Weitzman M, et al. Comparison of methods to detect visual field progression in glaucoma. Ophthalmology 1997:104:1228-36.

26 O'Brien C, Schwartz B. The visual field in chronic open angle glaucoma: the rate of change in different regions of the field. Eye 1990;4:557-62.

27 Wild JM, Hutchings N, Hussey MK, et al. Pointwise univariate linear regression of perimetric sensitivity against follow-up time in glaucoma. Ophthalmology 1997;104:808-15.
28 Spry PGD, Johnson CA. Identification of progressive glaucomatous visual field loss. Surv Ophthalmol 2002;47:158-73.

29 Spry PGD, Bates AB, Johnson CA, et al. Simulation of longitudinal threshold visual field data. Invest Ophthalmol Vis Sci 2000;41:2192-200.

30 Noureddin BN, Poinoosawmy D, Fitzke FW, et al. Regression analysis of visual field progression in low tension glaucoma. $\mathrm{Br} J$ Ophthalmol $1991 ; 75: 493-5$.

31 Birch MK, Wishart PK, Odonnell NP. Determining progressive visual field loss in serial Humphrey visual fields. Ophthalmology 1995: 102:1227-34.

32 Smith SD, Katz J, Quigley HA. Analysis of progressive change in automated visual fields in glaucoma. Invest Ophthalmol Vis Sci 1996;37:1419-28.

33 Viswanathan AC, Fitzke FW, Hitchings RA. Early detection of visual field progression in glaucoma: a comparison of Progressor and Statpac 2. Br J Ophthalmol 1997;81:1037-42.

34 Viswanathan AC, Hitchings RA, Fitzke FW. How often do patients need visual field tests? Graefes Arch Clin Exp Ophthalmol 1997;235:563-8.

35 Anderson DR, Davis EB. Sensitivities of ocular tissues to acute-pressure induced ischemia. Arch Ophthalmol 1975;93:267-74.

36 Hillman JS. Acute closed-angle glaucoma: an investigation into the effect of delay in treatment. Br J Ophthalmol 1979;63:817-21.

37 Ingram RM, Ennis JR. Acute glaucoma: results of treatment by bilateral simultaneous iridectomy, now without admission to hospital. Br J Ophthalmol 1983;67:367-71

38 McNaught El, Rennie A, McClure E, et al. Pattern of visual damage after acute angle closure glaucoma. Trans Ophthalmol Soc UK 1974;94:406-15.

39 Lowe RF. Clinical types of primary angle closure glaucoma. Aust NZ J Ophthalmol 1988;16:245-50.

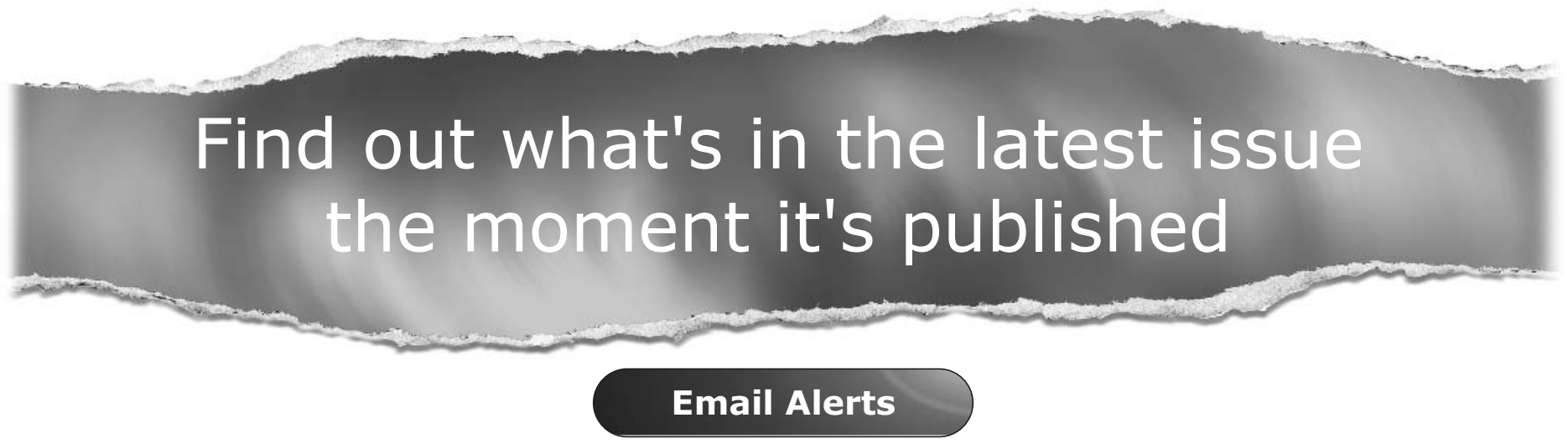

Sign up to receive the table of contents by email every month. You can select from three alerts:

Table of Contents (full), TOC Awareness (notice only); British Journal of Ophthalmology related announcements.

www.bjophthalmol.com 